\title{
Geografia e ensino: uma abordagem da climatologia dinâmica a partir do episódio de precipitação de granizo em 20 de outubro de 2007 no município de Santo Antônio das Missões/RS ${ }^{1}$
}

Resumo: Desenvolveu-se o conceito de clima no Ensino Médio baseado na análise da dinâmica climática. Explicou-se a análise rítmica identificando os tipos de tempo culminantes no episódio de granizo de 20 de outubro de 2007. Escolheu-se as turmas dos $1^{\circ}$ anos para a realização da atividade, primeiramente aplicando-se o Formulário 1 de avaliação preliminar e posteriormente apresentou-se a atividade, aplicandose o Formulário 2 avaliativo. Identificou-se a gênese do granizo, e a critério de avaliação, $68,5 \%$ dos alunos souberam identificar condições de tempo atmosférico e puderam conceituar de forma satisfatória tempo e clima. Na avaliação preliminar obteve-se apenas $27,5 \%$ dos alunos capazes de identificar e diferenciar os conceitos.

\section{Geography and education: an approach to dynamic climatology from the episode of rainfall in hail of 20 october 2007 in the city of Santo Antônio das Missões / RS}

\footnotetext{
Abstract: It was developed the concept of climate in high school based on the analysis of climate dynamics. It was explained the rhythmic analysis identifying the types of climate culminating in the hail episode of October 20,2007. It was chosen the first year classes to carry out this activity, first by applying the Form 1 of preliminary evaluation and subsequently it was presented the activity, applying the Form 2 of evaluation. It was identified the genesis of hail precipitation episode, and as evaluation criterion, $68,5 \%$ of the students could identify conditions of the atmospheric weather, as well as satisfactorily conceptualize weather and climate, in the preliminary evaluation it was obtained only $27.5 \%$ of the students able to identify and differentiate the concepts.
}

Arnaldo de Araújo Ribeiro* Maria da Graça Barros Sartori**
* Mestrando do Programa de Pós-graduação em Geografia Universidade Estadual Paulista 'Julio de Mesquita Filho", UNESP Campus Rio Claro, SP

** Professora Dra. Depto. Geociências UFSM, Santa Maria/RS

\section{Palavras-chave: \\ Ensino; \\ Climatologia Dinâmica; \\ precipitação de granizo \\ Key-words: Education; Dynamic Climatology; hail precipitation}

1 Artigo escrito a partir de Monografia de conclusão de curso em GeografiaLicenciatura; Universidade Federal de Santa Maria UFSM 2008. 


\section{Introdução}

Ao optar-se por uma metodologia baseada nos paradigmas do ritmo climático, Monteiro (1969, 1971), e do ritmo climático sul-rio-grandense por Sartori (2003), relaciona-se tais estudos a prática aqui desenvolvida, as quais se apresentam como pesquisa inédita para 0 ensino do clima na região Noroeste e Missões do Rio Grande do Sul.

O clima, ou mais precisamente o tempo atmosférico, é o principal fator ou elemento natural a exercer influência sobre as diversas atividades humanas. Segundo Tarifa et al (2006), a utilização do conhecimento cotidiano "estimula a percepção e a curiosidade dos alunos e, do ponto de vista didático, favorece sobremaneira o desenvolvimento da reflexão e observação em torno da elaboração de hipóteses explicativas no confronto direto com o objeto de estudo".

0 estudo do clima e do tempo deve partir do pressuposto da dinâmica atmosférica, já que sua manifestação ocorre mediante a evolução dos tipos de tempo configurados em "cadeias" nas sucessões mais habituais. A abordagem dinâmica do clima é um dos grandes avanços nos estudos desenvolvidos pela Climatologia Geográfica brasileira já que incorpora e busca a noção de ritmo climático. Essa concepção surge a partir dos estudos de Sorre (1951), que definiu 0 clima como "a série de estados atmosféricos acima de um lugar e em sua sucessão habitual", onde ganham destaque as interações entre os elementos climáticos. A partir dessa conceituação, o geógrafo brasileiro Carlos Augusto de Figueiredo Monteiro promove mudanças na abordagem climática, aplicando a noção de ritmo em trabalhos de climatologia.

O ritmo climático é definido pela análise rítmica Monteiro (1971). Sendo assim, é fundamental a caracterização e compreensão da circulação atmosférica na escala regional para uma melhor individualização do clima de qualquer lugar. Nessa perspectiva, entende-se a relevância da aplicação da noção de ritmo climático para o Ensino Médio, como forma de dar maior significado ao estudo e à percepção climática do aluno, e assim, verificar a aceitação, e comprovar a relevância e a eficácia dessa metodologia no Ensino.

Dessa forma, buscou-se responder aos anseios de alunos e professores do Ensino Médio no município de Santo Antônio das Missões - RS quanto à prática do ensino de climatologia, bem como identificar a participação dos sistemas atmosféricos e a sucessão dos tipos de tempo na região das Missões tendo o evento de precipitação de granizo como base para a análise diária, buscando-se verificar o quanto os alunos do Ensino Médio percebem a sucessão do tempo e se esta resulta em significados para o meio no qual estão inseridos.

\section{Material e Métodos}

Ao eleger-se o evento extremo de precipitação de granizo ocorrido em Santo Antônio das Missões como relevante para análise dinâmica em sala de aula, obteve-se os dados climáticos diários junto a Estação Meteorológica da Fundação Estadual de Pesquisa Agropecuária (FEPAGRO-RS). Selecionou-se, portanto, período entre os dias 15 e 23 de outubro, como forma

Geografia Ensino \& Pesquisa, v. 16, n.1, p. 117132, jan./jun. 2012

A Geografia e ensino: uma abordagem da climatologia dinâmica a partir do episódio de precipitação de granizo em 20 de outubro de 2007 no município de Santo Antônio das Missões/RS de mostrar aos alunos a gênese e evolução do tempo que culminou com o temporal de granizo do dia 20 de outubro de 2007. Entrou-se em contato com a Direção do Colégio Estadual Tolentina Barcelos Gonçalves, localizado no centro da cidade de Santo Antônio das Missões e verificou-se a possibilidade da aplicação e desenvolvimento da prática metodológica. Assim, enquadrou-se e escolheu-se a turma que mais se encaixasse no que se refere aos conteúdos a serem 
desenvolvidos e a escolha recaiu sobre as turmas do primeiro ano do Ensino Médio, da manhã, para a aplicação da proposta de metodologia de ensino, o público envolvido foi de 40 alunos.

Iniciou-se a compilação dos dados diários de precipitação $(\mathrm{mm})$, temperaturas máximas e mínimas diárias $\left({ }^{\circ} \mathrm{C}\right)$, direção do vento, umidade relativa (\%), pressão atmosférica (hpa). Foram utilizadas imagens de satélite referente ao evento de granizo em 20 de outubro NOA Aqua-NOA (INPE - DSA, 2008) disponíveis no sistema do CPTEC/INPE. Além disso, recorreu-se às cartas sinóticas do mês de outubro de 2007, obtidas junto à Marinha do Brasil no site do serviço meteorológico marinho (CHM, 2008). Assim, desenvolveu-se todo o processo de ensino e abordagem da climatologia dinâmica regional enfocando a cidade de Santo Antônio das Missões através da interpretação das imagens de satélite e dos gráficos da Análise Rítmica. Para a confecção dos gráficos de análise rítmica do período de 15 a 23 de outubro de 2007, recorreu-se ao programa Desenha (BORSATO et al, 2004). Assim definiram-se os tipos de tempo culminantes no temporal de granizo, sendo estes resultados apresentados aos alunos como método e como recurso didático para ensinar conceitos básicos de tempo e clima, bem como sua dinâmica.

Formulou-se, também, dois questionários (Quadros 1 e 2) de questões subjetivas e objetivas que foram aplicados junto às turmas. 0 primeiro serviu para identificar se os alunos compreendem a dinâmica climática do dia-a-dia, ou seja, a percepção do tempo e do clima. 0 segundo serviu para avaliar os resultados da aplicação da metodologia desenvolvida, para se ter melhor noção da eficácia do método proposto e também para constatar o nível de conhecimento adquirido pelos alunos das referidas turmas.

\section{Discussão dos Resultados}

Conforme um dos objetivos propostos para a pesquisa elaborou-se o primeiro questionário (Quadro 1) que foi aplicado aos alunos, formulário composto por questões abertas e subjetivas, que serviram para estimar o nível de entendimento dos alunos a respeito de clima e tempo, bem como as percepções dos mesmos a respeito da dinâmica climática local. A atividade foi realizada junto ao Colégio no dia 02 de outubro de 2008, ocasião na qual, teve-se o primeiro contato com as turmas 101 e 102, nessa oportunidade fez-se a apresentação do projeto, bem como os objetivos a serem alcançados com a colaboração dos alunos. Ao se analisar as respostas das questões aplicadas no questionário do Formulário 1 (Quadro 1), pôde-se avaliar 0 nível de conhecimento do grupo de alunos quanto às questões do clima e de sua dinâmica. $A$ questão 1 teve como objetivo identificar a compreensão dos alunos na diferença dos conceitos de tempo e clima.

Percebeu-se grande confusão na diferenciação desses conceitos por parte dos alunos. $\mathrm{Na}$ questão 1 apenas 11 alunos dos 40, responderam de forma satisfatória aos conceitos de tempo e clima, perfazendo apenas $27,5 \%$ do total do público envolvido. Estes $27,5 \%$, mesmo com dificuldades, conseguiram expressar suas idéias e identificar as diferenças de tempo e clima. Quanto ao texto descrito na questão 1, referente às condições de tempo em um dia hipotético, apenas 18 alunos, ou seja, 45\% da amostra, souberam responder se a situação descrita referiase ao tempo ou clima.

$\mathrm{Na}$ seqüência das questões, buscou-se verificar o entendimento dos alunos sobre os elementos e fatores do clima, avaliação que se tornou possivel mediante a análise das questões

Geografia Ensino \& Pesquisa, v. 16, n.1, p. 117132, jan.jun. 2012

Ribeiro, Arnaldo de Araújo; Sartori, Maria da Graça Barros

ISSN 2236- 4994 
2, 3, 4 e 5. Percebeu-se que nenhum dos 40 alunos soube argumentar respostas às questões, no sentido de perceber e diferenciar as influências dos elementos e fatores na caracterização do clima. A grande maioria fez confusões entre elementos e fatores climáticos. Nota-se, através da análise das respostas, que muitos dos alunos percebem os fatos relatados e evidenciados nas questões, fatos referentes ao lugar e às regiões abordadas, mas não sabem especificar os motivos e conceitos geográficos básicos para o entendimento do clima.

Através da questão 6 , buscou-se avaliar o quanto os alunos percebem e tem noção da dinâmica climática, bem como do tempo e a sua sucessão habitual. Dos 40 alunos, apenas 18 deles tiveram condição de responder à questão de forma satisfatória, pois deveriam fazer 0 relato das condições do tempo a partir do momento que saíram de suas casas naquele dia e como, possivelmente, o tempo se processaria ao longo daquele dia. Ou seja, $45 \%$ da turma conseguiu relatar o tempo atmosférico seguindo uma seqüência lógica de sucessão. Isso pode ser observado e exemplificado pelas respostas dadas por alguns dos 18 alunos, os quais responderam da seguinte forma à questão:

"Quando saí de casa o tempo estava nublado e abafado, agora mudou um pouco, 0 ar está mais frio e continua nublado. Eu acho que vai continuar assim, talvez chova no fim da tarde e tenha uma madrugada fria" (aluna, $1^{\circ}$ ano, T. 102).

"Estava nublado e relativamente úmido e agora ele continua nublado só que com nuvens mais pesadas, podendo até chover ao longo do dia ou da noite e com essa chuva irá esfriar um pouco no outro dia" (aluno, $1^{\circ}$ ano, T. 102).

Esta percepção da sucessão do tempo é possível de ser observada no dia-a-dia de qualquer pessoa, mesmo assim nota-se que grande parte dos jovens não tem noção e não percebem a dinâmica do tempo. Assim, 45\% dos alunos avaliados nesse primeiro momento da pesquisa têm visão da sequêencia mais lógica quanto à evolução dos estados do tempo, enquanto os outros $55 \%$ dos participantes não conseguiram estabelecer padrões lógicos de sucessão de tempo, e muitos deles não percebem nada a respeito do tempo atmosférico. 


\section{UNIVERSDADE FEDERAL DE SANTA MARIA CENTRO DE CIENCIAS NATURAIS E EXATAS CURSO DE GEOGRAFIA}

Trabalho de Graduaçăo de LicenciaturaII

Acadêmico: Arnaldo de Araúio R̉̉eiro

Exercício de avaliaçăo preliminar: compreensäo de conceitos de tempo e clima na disciplina de geografia no Ensino Médio.

Local: Colégio Estadual Tolentina Barcelos Gonçalves - Santo Antônio das Missöes - RS

Sérieiturma:

Participante dapesquisa:

1. Hoje amanheceu um dia muito bonito: ensolarado e com uma temperatura agradável. Assim que passou o meio-dia, mudou completamente. Começou a chover e a temperatura baixou. Pergunta-se: Esse texto refere-se ao tempo ou ao clima? Diferencie tempo e clima.

2. 0 clima e o tempo possuem elementos que säo responsáveis pelas características particulares de cada tipo de clima ou de tempo, especialmente a temperatura e a precipitaçäo. Como podem ser os climas de acordo com esses dois elementos?

3. A cidade de Belém, capital do estado do Pará, possui temperaturas médias altas por estar localizada próxima ao Equador $\left(0^{\circ}\right)$, enquanto Porto Alegre $-R S$ possui temperaturas médias mais baixas por estar mais afastada da linha do Equador. A que fator climático o texto se refere e como ele influi nas temperaturas?

4. As cidades de Santo Antônio das Missöes e de Caxias do Sul possuem o mesmo tipo de clims, ou seja, subtropical ou de latitudes médias. Porém, sabe-se que o clima de Caxias, localizada na Serra Gácha é mais frio e mais chuvoso que o de Santo Antônio das Missöes, localizado no Planalto, a oeste do RS. A que fator(es) climático(s) o texto se refere e como ele(s) influi(em) nas temperaturas e nas chuvas?

5. Santo Antônio das Missões, São Luiz Gonzaga e Säo Borja por exemplo, possuem temperaturas moito altas no veräo e muito baixas no invemo, o que siznifica elevadas amplitudes témicas armais. Qual(is) fator(es) climático(s)é (săo)responsável(eis)por essa diferença entre a temperatura média de verăo e de inverno?

6. Descreva conforme sua percepçäo:

A partir do momento que você sain de casa, pela manhä, como estava o tempo e como ele está neste momento? Como você acha que será sua evohuçäo ao longo do dia? Faça una breve descriçăo do que você observou.

Quadro 1 - Formulário de 1. Avaliação preliminar.

Org. RIBEIRO; SARTORI, 2008.

A exemplo dessa segunda situação transcreve-se uma das respostas observada na questão 6 :

"A hora que eu saí de casa ele não estava nem frio e nem calor, agora está mais friozinho. Como estará daqui a pouco eu não faço idéia. $O$ tempo está sempre mudando de clima então não há como imaginar o clima daqui à 1 hora, a variação ocorre muito rápida". (aluna, $1^{\circ}$ ano, T. 102)

Ao se analisar uma resposta como esta, percebe-se que, além de o indivíduo não possuir uma percepção em relação ao tempo atmosférico em seu dia-a-dia, ele também demonstra grande confusão entre os conceitos básicos de tempo e clima, demonstrando grandes deficiências por parte dos alunos envolvidos na pesquisa. 
Gênese do tempo a partir do episódio de precipitação de granizo em Santo Antônio das Missões

Analisou-se precipitação de granizo ocorrido no dia 20 de outubro de 2007, que assolou de forma drástica o município de Santo Antonio das Missões. Nessa ocasião, mais de $90 \%$ das residências e prédios públicos e comerciais na cidade tiveram danos bastante significativos, conforme levantamento realizado pela Prefeitura Municipal e Defesa Civil. Assim, tendo como critério a relevância atribuída a esse evento, julgou-se importante fazer essa abordagem frente aos alunos em sala de aula, uma vez que o episódio de granizo foi bastante significativo, gerando caos e afetando diretamente os alunos participantes da atividade pedagógica.

Para essa análise selecionou-se o período entre 15 e 23 de outubro. Definiram-se as condições atmosféricas e determinou-se os tipos de tempo nesses dias e, mais especificamente, no dia 20 de outubro, data do sinistro. Conforme o padrão das variáveis atmosféricas observadas na Figura 1, percebe-se, nesse intervalo de dias, a individualização de um ciclo correspondendo às Fases: Frontal, Transicional, Pré-frontal, Frontal e Domínio Polar, conforme SARTORI (1979).

No dia 15 de outubro, o tempo caracterizou-se, conforme a análise, pela fase Frontal, ou seja, presença da Frente Polar Atlântica, pois os elementos atmosféricos plotados no gráfico de análise rítmica (Figura 1) apresentaram queda da pressão atmosférica que desceu aos 1017 hpa, a amplitude térmica passou a elevar-se a partir desse dia, marcando mínimas e máximas de $16^{\circ} \mathrm{C}$ e $22^{\circ} \mathrm{C}$, respectivamente. A umidade relativa do ar estava elevada, mas entrou em declínio a partir de então; no dia 15 a umidade atingiu $90 \%$, mas não foi registrada precipitação e os ventos foram variáveis indicando o domínio de tempo causado pela influência da passagem frontal, como pode ser visto nas imagens de satélite (Figura 2), onde o Estado encontra-se ainda sob influência da nebulosidade associada à frente fria.

As observações dos elementos atmosféricos para os dias 16, 17 e 18 de outubro, permitiram concluir o domínio da fase Transicional, uma vez que o Anticiclone Polar não dominou de forma a definir o tipo de tempo Anticiclônico Polar Marítimo após a passagem da frente. 


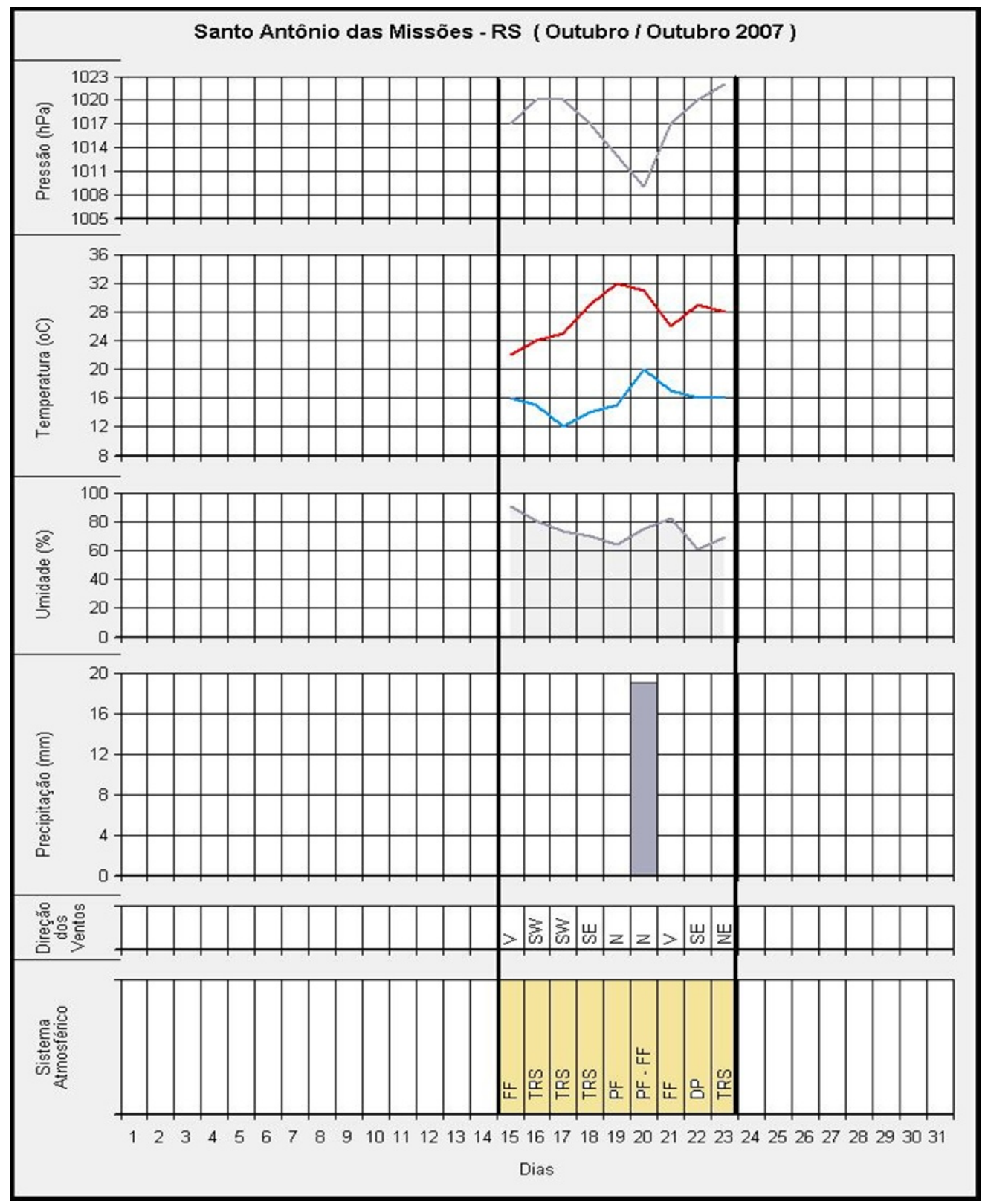

Figura 1- Gráfico de análise rítmica entre os dias 15 e 23 de outubro/2007 em Santo Antônio das Missões - RS. Fonte dos dados: Estação Meteorológica da FEPAGRO (São Borja/RS).

Org. Ribeiro, 2008

Legenda: Período de análise. Fases de tempo identificadas: DP - Domínio Polar; TRS - Transicional; PF - Pré-

frontal; FF - Frontal Frente Fria.

Temperaturas $\left({ }^{\circ} \mathrm{C}\right)$ : ------ Temperaturas Máximas ------ Temperaturas Mínimas. 


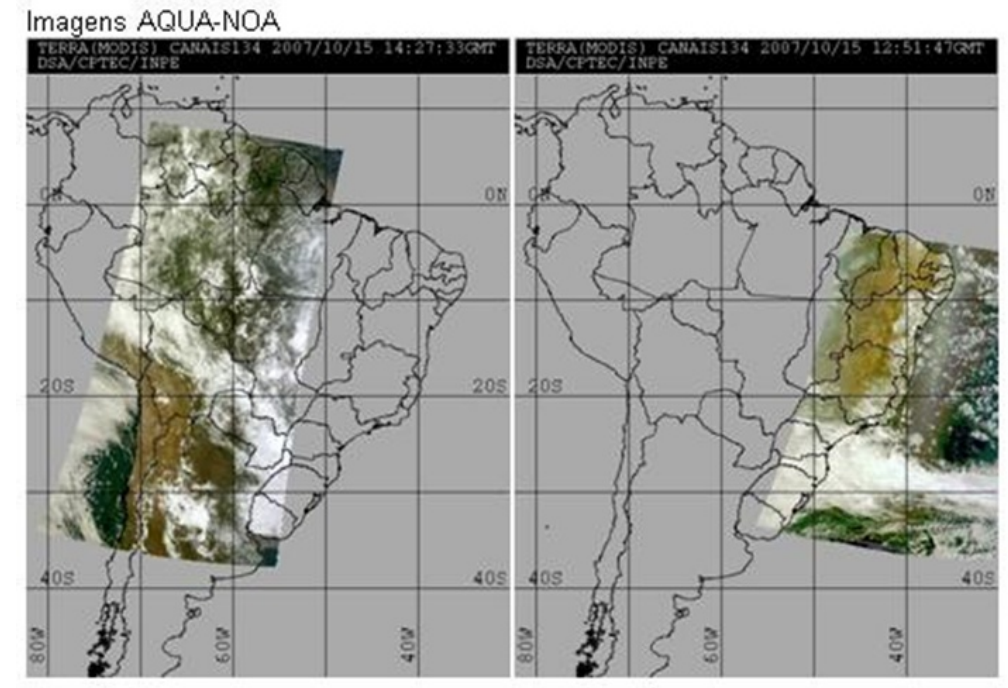

Figura 2-Imagens AQUA-NOA do dia 15 de outubro de 2007.

No dia 16, ainda, conforme os dados meteorológicos e imagens do satélite AQUA-NOA (Figura 3-A) percebe-se influência da frente fria mais sobre o litoral norte do RS. Assim para a região noroeste do Estado já se define a fase Transicional atuando diretamente e, como pode ser visto na Figura 1, para esse dia, a pressão atmosférica elevou-se em comparação ao dia anterior, alcançando $1020 \mathrm{hpa}$, a amplitude térmica aumentou, a umidade relativa caiu pra volta de $80 \%$, a direção do vento passou a predominar do sudoeste em grande parte do dia, não registrando chuva. Essas características indicam a definição do tempo Anticiclônico em Tropicalização com domínio da Massa Polar Velha. Os dias 17 e 18, o tempo ainda se manteve sob a fase Transicional. Conforme os dados do gráfico de análise rítmica, a pressão atmosférica se manteve no dia 17, vindo a declinar para 1017 hpa no dia 18, a amplitude térmica aumentou chegando a valores máximos e mínimos de $29^{\circ} \mathrm{C}$ e $14^{\circ} \mathrm{C}$, respectivamente, a umidade relativa esteve em declínio no dia 18 e os ventos sopraram predominantemente de sudoeste e sudeste nos dois dias.

Essas características juntamente com a observação das imagens de satélite (Figuras 3-B e 3-C) mostram o afastamento da nebulosidade associada ao sistema frontal (FPA) e manutenção da fase Transicional sobre o território gaúcho.
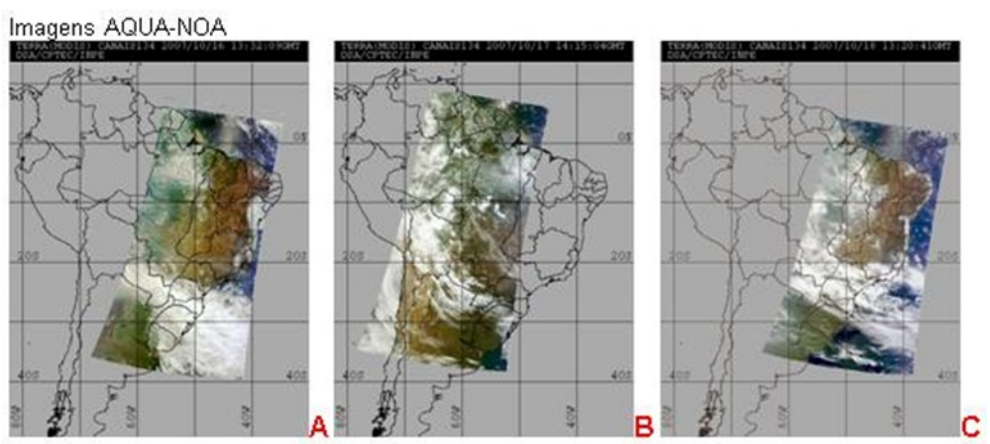

Figura 3 - Imagens AQUA-NOA do dos dias 16(A), 17(B) e 18(C) de outubro de 2007.

A Geografia e ensino: uma abordagem da climatologia dinâmica a partir do episódio de precipitação de granizo em 20 de outubro de 2007 no município de Santo Antônio das Missões/RS
Já no dia 19 definiu-se a fase Pré-frontal com domínio ainda do Tempo Anticiclônico Polar em Tropicalização (Figura 1), o vento passou a predominar da direção norte na maior parte do dia, a pressão atmosférica se manteve baixa, em relação aos dias anteriores, as temperaturas 
máxima e mínima aumentaram atingindo significativa amplitude térmica diária, e a umidade relativa das $12 \mathrm{~h}$ diminuiu, chegando a $65 \%$. A análise da imagem de satélite (Figura 4) mostra condições de céu limpo sobre a região, mas também nos confirma a situação Pré-frontal, uma vez que se observa a aproximação de nebulosidade associada à formação de uma frente fria (FPA) sobre o território argentino.

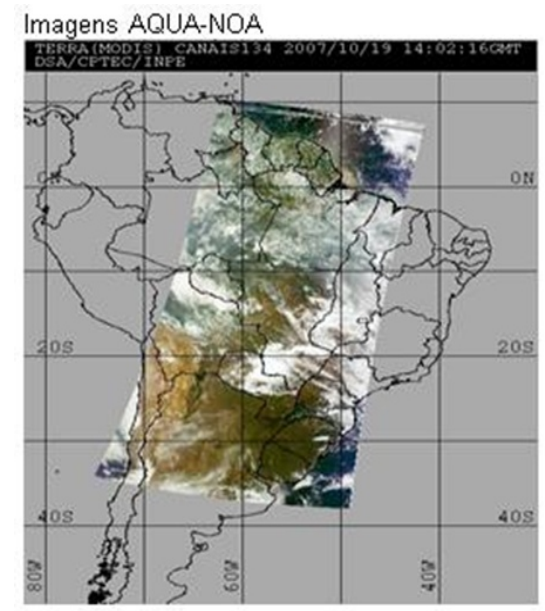

Figura 4 - Imagem AQUA-NOA do dia 19 de outubro de 2007.

As condições atmosféricas do dia 20 quando aconteceu o temporal com granizo em Santo Antônio das Missões, podem ser observadas na Figura 1, bem como na imagem de satélite Figura 5 e no mapa sinótico Figura 6 . Nesse dia, nota-se queda significativa da pressão atmosférica, a qual desceu a $1009 \mathrm{hpa}$, a temperatura mínima elevou-se significativamente se comparada aos dias anteriores chegando a $20^{\circ} \mathrm{C}$, e o vento predominou da direção norte. Ao longo do período, registrou-se aumento da umidade relativa e precipitação alcançando $19 \mathrm{~mm}$, esta acompanhada de granizo intenso. Ao analisar, a imagem de satélite e a carta sinótica do dia, juntamente com os dados registrados pela Estação Meteorológica, pode-se constatar que a maior parte do dia predominou a fase Pré-Frontal com domínio do Tempo Anticiclônico Polar em Tropicalização, o qual evoluiu para tempo Frontal de Sudoeste no decorrer do período.

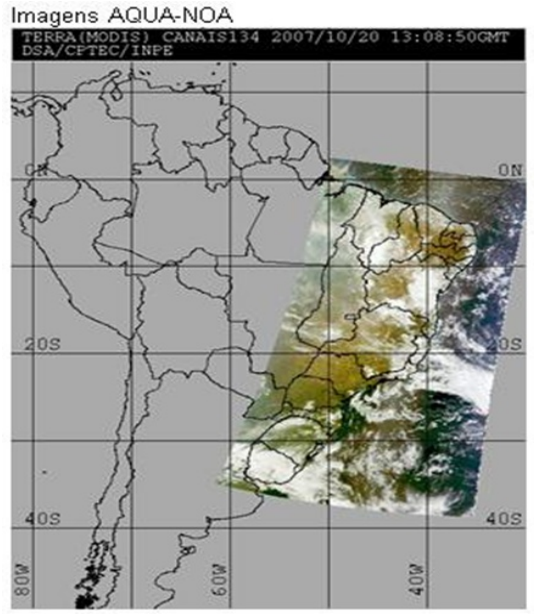

Figura 5-Imagem AQUA-NOA do dia 20 de outubro de 2007.

Atribui-se ao episódio da precipitação de granizo, gênese relacionada à conjunção de fatores ligados a instabilidades pré-frontais, formadas pelo calor originário do norte da Argentina e Paraguai, instabilidades estas que se definem com a aproximação da Frente Polar Atlântica

Geografia Ensino \& Pesquisa, v. 16, n.1, p. 117132, jan.jun. 2012

Ribeiro, Arnaldo de Araújo; Sartori, Maria da Graça Barros

ISSN 2236- 4994 
que se encontrava sob território uruguaio no início do dia 20. Como pode ser visto no sistema de nuvens sobre o sul do Brasil (Figura 5), há um complexo convectivo a noroeste do Rio Grande do Sul associado às instabilidades pré-frontais, observado na dianteira da nebulosidade correspondente a frente fria em aproximação.

\section{Carta Sinótica: Dia 20 de outubro 2007}

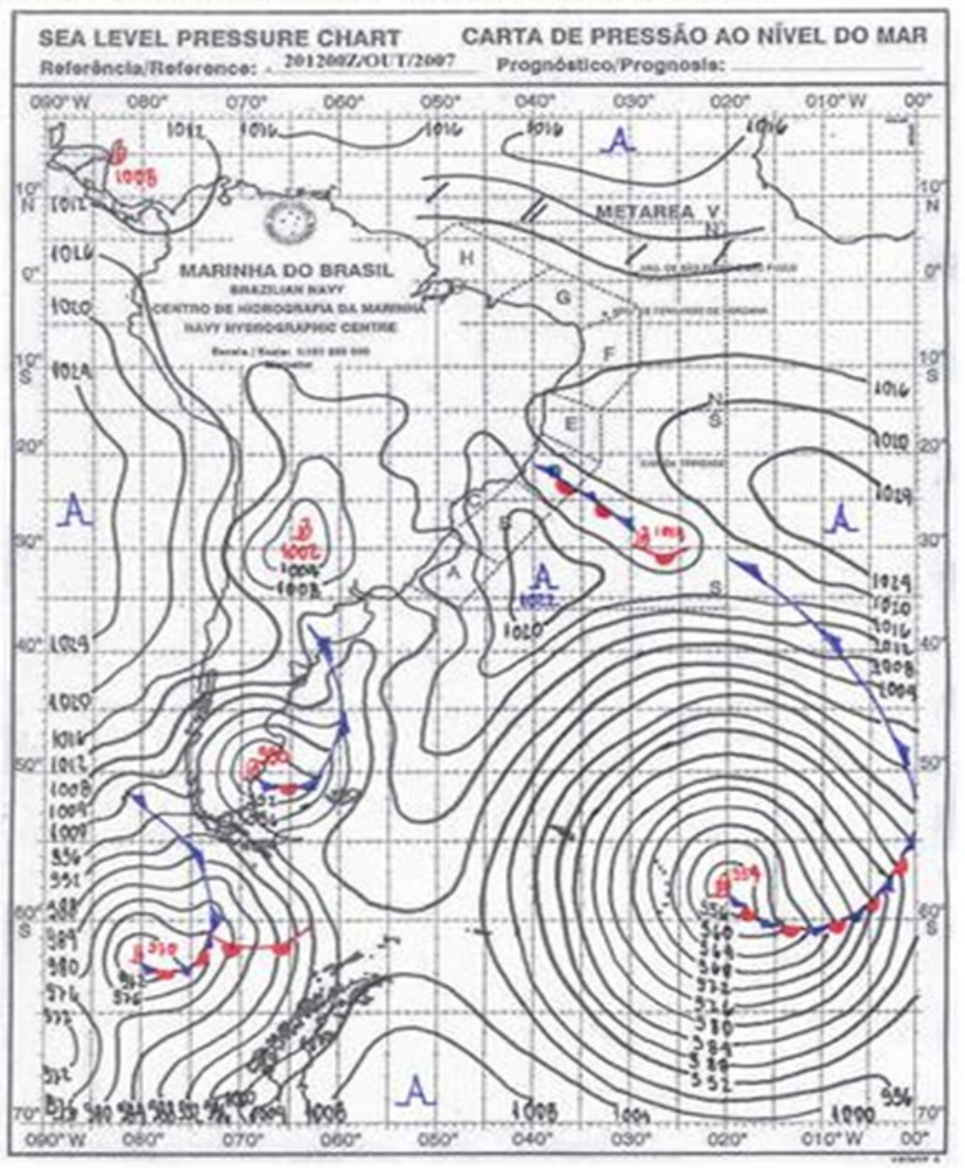

Figura 6- Carta Sinótica de Superfície do dia 20 de outubro de 2007

Essa conjunção de sistemas atmosféricos maximizou o potencial das nuvens geradas pela aproximação da Frente Polar Atlântica, gerando nuvens do tipo Cumulunimbus de atividade convectiva intensa e potencialmente geradora de granizo e vento fortes. 0 padrão sinótico da Figura 6 mostra, de fato, a aproximação do sistema frontal (FPA), e associado ao seu deslocamento, a formação de células de baixa pressão atmosférica, originária no norte da Argentina, antecedendo a chegada da frente, as quais se propagaram sobre a região Noroeste do RS.

Possivelmente, a passagem frontal, no período da noite entre os dias 20 e 21, conjugada às células de baixa pressão pré-frontal, contribuíram para intensificar o processo de formação das nuvens de grande desenvolvimento vertical e grande potencial para formação de granizo,

Geografia Ensino \& Pesquisa, v. 16, n.1, p. 117 132, jan./jun. 2012

A Geografia e ensino: uma abordagem da climatologia dinâmica a partir do episódio de precipitação de granizo em 20 de outubro de 2007 no município de Santo Antônio das Missões/RS causando ventos fortes e precipitação extrema de granizo sobre pontos isolados da região Noroeste do RS, afetando de forma severa o Município.

No dia 21 predominou a fase Frontal com tempo instável, mas sem precipitação, derivado da presença da Frente Polar Atlântica.

Assim, pode-se observar as variáveis atmosféricos na Figura 1, com ventos de direções variáveis e umidade relativa em alta (81\%), bem como certa elevação da pressão atmosférica, a 
qual sinaliza a aproximação da Massa Polar Atlântica subseqüente à Frente, uma vez que o sistema de nebulosidade associado a ela afasta-se do Estado, mais especificamente da região Noroeste, indo em direção a Santa Catarina, como pode ser constatado na imagem de satélite da Figura 7-A.

No dia 22 de outubro, de fato houve o domínio da Massa Polar Atlântica, quando os ventos passaram a predominar de sudeste, a umidade relativa caiu a $60 \%$, e a amplitude térmica aumentou (Figura 1). Percebe-se, ainda, o aumento da pressão atmosférica que nesse dia alcançou 1020 hpa. Nessa ocasião o domínio do tempo "bom", ausência de chuva e nebulosidade, como pode ser visto na Figura 7-B. Ou seja, nesse dia e nos dias que se seguiram, houve o domínio do Anticiclone Polar Atlântico, conseqüentemente do Tempo Anticiclônico Polar Marítimo, o qual evoluiu para a fase Transicional no dia 23.

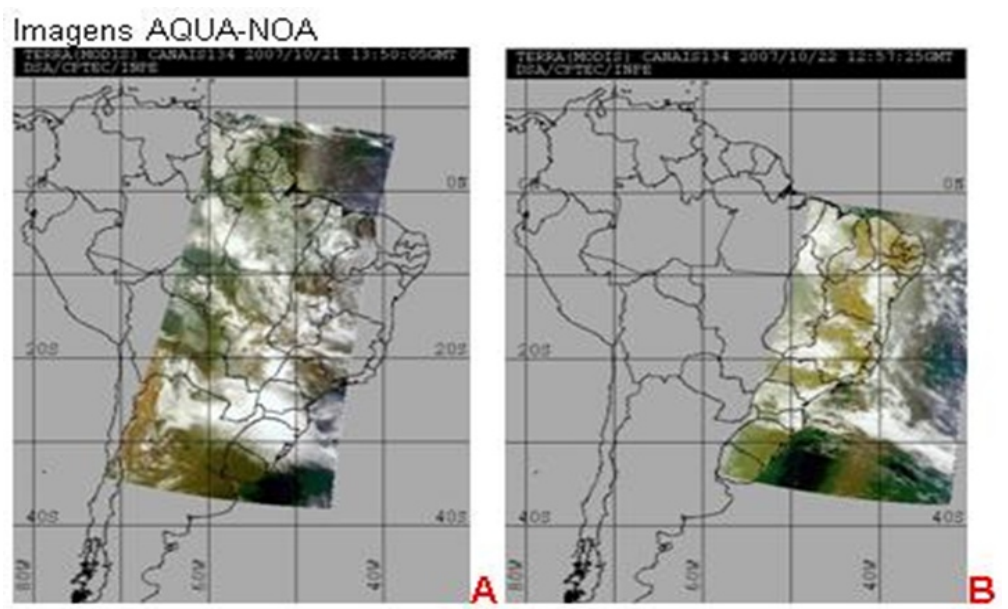

Figura 7- Imagens AQUA-NOA dos dias 21(A) e 22(B) de outubro de 2007.

Na perspectiva de propor alternativas ao ensino do clima na Escola, fez-se a partir dessa análise acima apresentada, a aplicação, conforme o objetivo do trabalho, da metodologia para definição do ritmo climático no estudo do clima no Ensino Médio. Definiu-se a gênese e evolução do tempo que culminou no episódio de granizo em Santo Antônio das Missões, cuja temática aguçou, sobremaneira, o interesse dos alunos para com a atividade. Assim, organizou-se a apresentação em aula da análise rítmica como forma de consolidar a metodologia aplicada. Explicou-se a gênese do tempo referente ao evento de granizo, que causou ainda maior interesse dos alunos pela aula. Teceram-se algumas considerações a respeito do exposto, e dos objetivos que se buscava atingir com a atividade.

Foram apresentadas aos alunos e professores, as fontes, bibliografias consultadas para a apresentação e colocadas à disposição e ao conhecimento os "sites" que apresentam, de certa forma, uma abordagem climática a partir da dinâmica atmosférica através dos imageamentos de satélite e cartas sinóticas, bem como alguns materiais educacionais sobre meio ambiente, ciências atmosféricas e mudanças ambientais globais. Na atividade desenvolvida no Colégio, aplicou-se o Formulário 2 na sequêencia da atividade, como forma de avaliar o aproveitamento e relevância da proposta didático-pedagógica junto às turmas Quadro 2.

As questões abertas de número 1, 2 e 3 (Quadro 2), objetivaram estabelecer comparação com os resultados prévios obtidos com a aplicação do Formulário 1 (Quadro 1) e assim constatar os resultados perante o entendimento do conteúdo abordado. Constatou-se melhor

Geografia Ensino \& Pesquisa, v. 16, n.1, p. 117 . 132, jan.jun. 2012

Ribeiro, Arnaldo de Araújo; Sartori, Maria da Graça Barros

ISSN 2236- 4994 
rendimento nas respostas, principalmente sobre a identificação das fases do tempo e da diferenciação dos conceitos de tempo e clima. Conforme a avaliação das respostas à questão 1 (Quadro 2) $68,5 \%$ dos alunos souberam identificar o que foi perguntado considerando ser representativo das condições de tempo atmosférico, bem como puderam conceituar, de forma satisfatória, tempo e clima, diferenciando-os. Pode-se constatar e exemplificar por meio da transcrição de algumas respostas dadas por alguns dos 24 participantes $(68,5 \%)$, os quais responderam da seguinte forma à questão 1 :

"Ao tempo: o tempo pode mudar de um momento para outro; o clima é estável e para estudá-lo é necessário anos de observação". (aluna, $1^{\circ}$ ano T.102).

"Refere-se ao tempo. Tempo: representa as condições atmosféricas de um determinado lugar em um momento. Clima: é algo duradouro, é uma sucessão habitual dos tipos de tempo num determinado lugar." (aluna, $1^{\circ}$ ano T. 101).

\section{UNTVERSIDADE FEDERAI DE SANTA MARIA \\ CENTRO DE CIENCLAS NATURAIS E EXATAS CURSO DE GEOGRAFIA}

\section{GEO GRAFLA E ENSINO: UMAABORDAGEM DA CLDMATOLOGIA DINAMUCA PARA 0 ENSINO MEDIO E A SUCESSA DOS TIPOS DE TEMTO NO MUNICIFIO DE SANTO ANTÖLIO DAS MUSS ÓES - RS}

Trabatho de Gabag̃o II: Gecgrafialicenciarta

Acadênico: Amsilo deAríno Fìín

\section{Formulário 2 - Questionário de Avaliaçăo}

Local: Colégio Estadual Tolentina Barcelos Gonçalues - Sarto Artônio das Missöes - RS Farticipante daperpuisa:

Sériettrma: Inade:

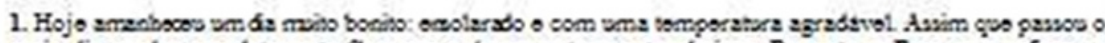

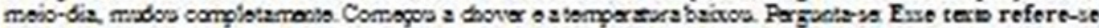
20 tempo on ao clima? Diferescie tempo o clima.

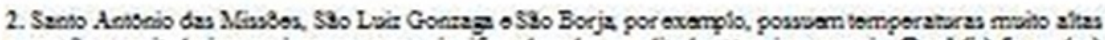

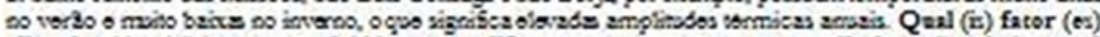

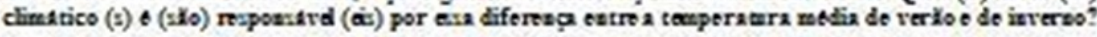

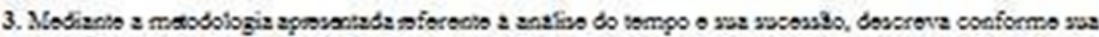
porcop; 20 :

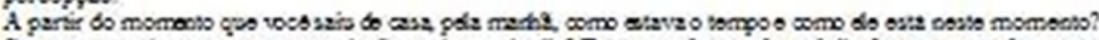

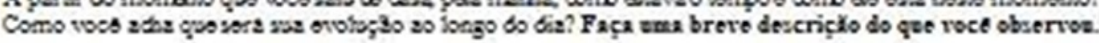

4. A respeito da atrijlade apresentada:

A) Como vocs avalie o dounvohimoato de atividado para as asias do goografia?

() mriso bom ( ) bom ( ) indiforecto

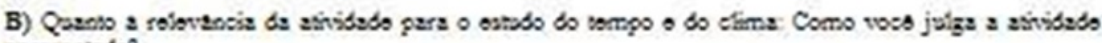
speosontade?

() mrato boa ( ) bos ( ) indiferecte

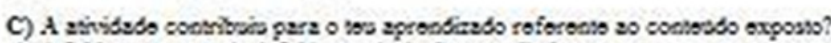

() foi importants ( ) foi boa (') nlo contribjis

5) Cosciderasdo o sea apreadiado peraste a atividade:

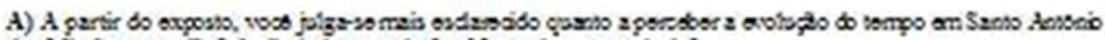
des Masoses o rogivo? Arribjiodo sota do 5 a 10 , qual vocs is deria?

Geografia Ensino \& Pesquisa, v. 16, n.1, p. 117 132, jan./jun. 2012

A Geografia e ensino: uma abordagem da climatologia dinâmica a partir do episódio de precipitação de granizo em 20 de outubro de 2007 no município de Santo Antônio das Missões/RS $\left(\right.$ ) 5()$\left.^{6}()^{7}()\right) 8() \theta() 10$.

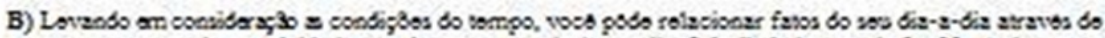

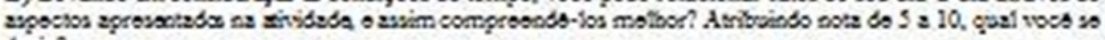
deria?

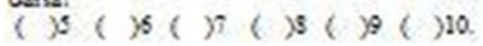

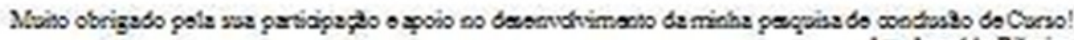
All Aravido Riboiro

Quadro 2 - Formulário 2 para avaliação da atividade. Org. Ribeiro; Sartori, 2008 
Resgatando-se o resultado obtido na avaliação preliminar sobre a questão 1 formulário 1 (Quadro 1), apenas $27,5 \%$ dos alunos souberam naquela oportunidade identificar e diferenciar os conceitos.

Quanto à questão 2 do Formulário de avaliação (Quadro 2), que objetivou concluir se os alunos passaram a entender e compreender as diferenciações entre os elementos e fatores climáticos, a análise das respostas revelou que, 37,14 \% souberam argumentar a respeito da questão, sendo um percentual relativamente baixo, mas, comparando-se com o levantamento feito preliminarmente no questionário 1 (Quadro 1), naquela oportunidade nenhum dos alunos soube argumentar a respeito da mesma questão, a qual foi reaplicada posteriormente à apresentação da atividade.

A questão 3 do Formulário 2 foi reaplicada nessa segunda oportunidade pós explanação em sala de aula da proposta desse trabalho. Esta questão objetivava constatar a percepção do aluno perante a variação diária do tempo após a prática desenvolvida, visando avaliar a aprendizagem a partir da identificação e análise da dinâmica atmosférica. Assim, mediante a análise das respostas julgou-se satisfatória, pois $68,57 \%$ das colocações feitas pelos alunos foram corretas, comparando-se com a mesma questão aplicada no Formulário 1 (Quadro 1), teve-se aumento na porcentagem, uma vez que naquela oportunidade apenas $45 \%$ dos alunos tiveram condições de relatar o tempo atmosférico com certa coerência.

Mas aqui cabe destacar que foi constatada pouca evolução no que se refere aos conteúdos e consistência nos relatos, não se percebendo grandes diferenças quanto às respostas obtidas no Formulário 1. Este fato pode ser em parte, atribuído certamente a pouca maturidade dos alunos perante a argumentação lógica apresentada na explicação teórica, conhecimento abstrato a partir do meio envolvente, uma vez que a maioria dos alunos $(62,8 \%)$ tem apenas 15 anos de idade, o que provavelmente influenciou na pouca evolução quanto à percepção do tempo atmosférico. Portanto, afirma-se a dificuldade de manter a atenção dos alunos e motivá-los "a deixar a preguiça de lado" e a participarem ativamente das atividades em sala de aula.

Referindo-se às questões objetivas de avaliação da atividade e quanto ao aprendizado do aluno perante a prática, constatou-se excelente avaliação da metodologia aplicada em sala de aula. As questões 4 ( $\mathrm{A}$ e B) do Formulário 2 foram articuladas de forma a que se pudesse concluir a respeito da receptividade dos alunos perante as novas propostas metodológicas para o ensino da geografia, aqui especificamente o estudo do clima. Como pode ser visto no Quadro 3 , a avaliação da atividade foi muito positiva.

\begin{tabular}{|c|c|c|}
\hline $\begin{array}{c}\text { NÍVEL DE ACEITAÇÃO DA } \\
\text { PRÁTICAAPRESENTADA }\end{array}$ & QUESTÃO 4A & QUESTÃO 4 B \\
\hline Muito boa & 23 participantes $(65,7 \%)$ & 20 participantes $(57,1 \%)$ \\
\hline Boa & 12 participantes $(34,2 \%)$ & 15 participantes $(42,8 \%)$ \\
\hline Indiferente & - & - \\
\hline
\end{tabular}

Quadro 3-Avaliação da atividade apresentada, segundo as respostas às questões $4 \mathrm{Ae} \mathrm{B}$ do Formulário 2. Org. Ribeiro, 2008.

A questão $4 \mathrm{C}$ do Formulário 2 serviu para avaliar o aprendizado referente ao conteúdo exposto, e, 30 alunos julgaram a atividade muito importante para o aprendizado do correspondendo a $85,7 \%$ do total de participantes, os outros 5 consideraram-na boa, perfazendo

Geografia Ensino \& Pesquisa, v. 16, n.1, p. 117 132, jan.jun. 2012

Ribeiro, Arnaldo de Araújo; Sartori, Maria da Graça Barros

ISSN 2236- 4994 
14, 2\%. A questão 5 do Formulário 2 solicita a auto-avaliação dos alunos no que se refere ao aproveitamento frente a atividade desenvolvida, a qual atribuíram notas de 5 a 10. Na questão 5 A foi perguntado se 0 aluno julgava-se mais esclarecido quanto a entender a evolução do tempo em Santo Antônio das Missões e região, a partir da atividade apresentada, e 12 alunos atribuíram-se nota 9, também 12 atribuíram-se nota 8, 8 alunos se deram nota 7 e 3 deram-se nota 10,0 que pode ser considerado, assim, que a atividade foi bastante relevante para 0 aprendizado do conteúdo. Na questão 5-B foi indagado, ainda quanto à auto-avaliação, se os alunos a partir de então poderiam relacionar fatos do seu dia-a-dia aos aspectos apresentados na atividade, e assim compreendê-los melhor. Nesta questão foram atribuídas notas 10 por 6 alunos, nota 9 por 13 alunos, 8 por 10 alunos, 7 por 5 alunos e nota 6 por apenas 1 aluno. Foi, portanto, muito positiva a avaliação de desempenho obtida pelos alunos levando, em consideração os aspectos subjetivos quanto ao aproveitamento e aprendizado do conteúdo perante a atividade proposta e desenvolvida neste trabalho.

\section{Considerações Finais}

Considera-se a relevância do estudo do clima no Ensino Médio como base na metodologia aqui apresentada, de modo a contemplar a interface sócio-ambiental da percepção local e regional, o qual promoveu melhor entendimento da abordagem da climatologia, uma vez que se levou em conta a dinâmica climática do espaço vivido pelo aluno. Nesse sentido, o objetivo maior do trabalho foi plenamente alcançado, tendo sido apresentado os conceitos de tempo e de clima propondo-se novas abordagens para o Ensino Médio, através da análise da dinâmica climática. Assim, foi de êxito a mobilização alcançada com os alunos e com os professores que se envolveram no desenvolvimento da atividade.

Avaliou-se 0 nível de conhecimento discente das duas turmas do $1^{\circ}$ ano, quanto aos conteúdos de clima, considerando a dinâmica atmosférica local. Assim, num primeiro momento da apresentação do projeto e aplicação do Formulário 1 (Quadro 1), as respostas foram insatisfatórias, uma vez que os alunos ainda não tinham tido contato com o conteúdo que seria trabalhado no decorrer do trimestre pela professora titular das turmas, e ainda não percebiam e entendiam o tempo atmosférico no seu dia-a-dia. A partir da abordagem dinâmica do clima e do uso da técnica de análise rítmica, obteve-se bastante êxito quanto à análise das variáveis atmosféricas e das imagens de satélite para o período de 15 a 23 de outubro de 2007. Enfatizou-se a relevância da atividade desenvolvida com a exemplificação da dinâmica atmosférica que explica a gênese do evento meteorológico que resultou no temporal de granizo, etapa do trabalho que despertou grande interesse dos alunos.

Sendo assim, comprovou-se a eficácia da metodologia da análise rítmica, proposta por Monteiro, (1971), e sua aplicabilidade ao Ensino de Climatologia Geográfica. Comprovou-se 0 melhor rendimento nas respostas dos alunos, principalmente sobre a identificação das fases do tempo e da diferenciação dos conceitos de tempo e clima. Conclui-se, também, a excelente avaliação da metodologia aplicada em sala de aula por parte dos alunos e professores, mostrando a importância de se procurar apostar em alternativas diferenciadas para o ensino de Geografia.

A proposta didático-pedagógica contribuiu para 0 rol de pesquisas em metodologias de estudo do clima brasileiro e sul-rio-grandense segundo a visão geográfica, servindo como fonte

climatologia dinâmica a partir do episódio de

precipitação de granizo em 20 de outubro de

2007 no município de Santo Antônio das Missões/RS 
teórico-metodológica que motive e sirva de apoio para o desenvolvimento de outros trabalhos que venham compensar as carências da prática docente na Educação Básica.

\section{Bibliografia}

BORSATO, V. DA. A.; BORSATO, F. H.; FILHO, E. S. Análise Rítmica e a variabilidade Têmporo-Espacial. In: VI Simpósio Brasileiro de Climatologia Geográfica. 6., 2004, Aracaju. Anais... Aracaju, 2004. 1 CD-ROM.

CENTRO DE HIDROGRAFIA DA MARINHA - CHM. Serviço Meteorológico Marinho. Niterói, 2008. Disponivel em: <http://www.mar.mil.br/dhn/chm/meteo/prev/cartas>. Acesso em: $1^{0}$ ago. 2008.

INSTITUTO NACIONAL DE PESQUISAS ESPACIAIS. INPE - Divisão de Satélites e Sistemas Ambientais. São José dos Campos, 2008. Disponível em: < http://satelite.cptec.inpe.br/home/\#>. Acesso em: $1^{0}$ ago. 2008.

MONTEIRO, C. A. F. A Frente Polar Atlântica e as chuvas na fachada sul - oriental do Brasil. São Paulo: Instituto de Geografia da USP, 1969. Série Teses e Monografias 1.

Análise rítmica em climatologia - problemas da atualidade climática em São Paulo e achegas para um programa de trabalho. Revista IGUSP. São Paulo. [s./V.], [s./n.], p. 1-21, 1971.

SARTORI, M. G. B. 0 clima de Santa Maria: do regional ao urbano. São Paulo. Departamento de Geografia, Faculdade de Filosofia, Letras e Ciências Humanas da Universidade de São Paulo, 1979. Dissertação (Mestrado em Geografia).

SARTORI, M. G. B. A dinâmica do clima do Rio Grande do Sul: indução empírica e conhecimento científico. Revista Terra Livre, São Paulo, v.1, n.20, p. 27-49, jan.jul. 2003.

SORRE, M. Les fondements de la Géographie Humaine. Paris: Armand Colin, 1951.

TARIFA, J. R.; SETTE, D. M.; TELÉSFORO, H. A. Os climas e a práticas no ensino fundamental e médio. In: VII Simpósio Brasileiro de Climatologia Geográfica. 2006. Rondonópolis. Anais... Rondonópolis: Universidade Federal do Mato Grosso, 2006. 1.CD-ROM.

\section{Correspondência:}

Arnaldo de Araújo Ribeiro - Avenida Quinze 232. Apto 10. Condomínio Thomaz. Bairro Saúde. Rio Claro -SP. Cep:13500330

E-mail: ribeirogeo@yahoo.com.br

Recebido em 14 de setembro de 2011

Revisado pelo autor em 15 de outubro de 2011

Aceito em 24 de novembro de 2011 